\title{
Isolated Gastrointestinal Graft versus Host Disease in a Patient of Multiple Myeloma after Autologous Hematopoietic Stem Cell Transplantation
}

\section{Garg A, Yadav S and Nityanand S*}

Department of Hematology, Sanjay Gandhi Post Graduate Institute of Medical Sciences, India

*Corresponding author: Nityanand S, Department of Hematology, Sanjay Gandhi Post Graduate Institute of Medical Sciences, Rae Bareli Road, Lucknow 226014, India

Received: February 28, 2017; Accepted: March 14, 2017; Published: March 31, 2017

\begin{abstract}
Acute graft versus host disease (GVHD) occurs in $50-70 \%$ of patients undergoing allogeneic Hematopoietic Stem Cell Transplantation (HSCT) and is a major cause of post transplantation morbidity and mortality. A syndrome similar to acute GVHD has been reported after autologous HSCT, and has been termed autologous GVHD (auto GVHD). We report a case of multiple myeloma who developed gastrointestinal GVHD, following an autologous HSCT. During the course of the transplant, patient developed severe diarrhoea. Repeated stool examinations showed no pus cells/RBCs, no ova/cyst, no opportunistic pathogens, giardia antigen was negative, and bacterial and fungal cultures were negative. The PCR for CMV was negative; serology for EBV and hepatitis $A, E, B$ and $C$ viruses was negative. The Clostridium difficile toxin assay was negative. LFTs were normal. Despite administration of systemic antimicrobials, anti-motility drugs, anti-secretory drugs and probiotics, the diarrhoea was persistent. The rectal biopsy showed features of GVHD, and was negative for CMV, fungi and acid fast bacilli. The patient was started on methylprednisolone @ $2 \mathrm{mg} / \mathrm{kg} /$ day in two divided doses. There was a dramatic improvement in the nausea and diarrhoea and the anti-motility and anti-secretory agents could be stopped. Isolated GI GVHD is rare but should be considered in the differential diagnosis of severe unexplained diarrhoea following auto HSCT and appropriate investigations including endoscopy and possibly mucosal biopsy should be undertaken to document the diagnosis and initiate early therapy with steroids.
\end{abstract}

Keywords: Myeloma; GVHD; Transplant

\section{Abbreviations}

GVHD: Graft versus Host Disease; HSCT: Haematopoeitic Stem Cell Transplant; GI: Gastro-intestinal; MM: Multiple Myeloma

\section{Introduction}

Acute graft versus host disease (GVHD) occurs in 50-70\% of patients undergoing allogeneic Hematopoietic Stem Cell Transplantation (HSCT) and is a major cause of post transplantation morbidity and mortality [1]. A syndrome similar to acute GVHD has been reported after autologous HSCT, and has been termed as autologous GVHD (auto GVHD) [2]. We report a case of multiple myeloma who developed isolated gastrointestinal (GI) GVHD, following an autologous HSCT.

\section{Case Presentation}

A 60 year old gentleman with IgG-lambda multiple myeloma was diagnosed at our centre in December 2012. He was treated with Thalidomide and dexamethasone. After completion of 6 cycles, the disease was in complete remission, and he was taken up for an autologous HSCT. Stem cell mobilization was done using cyclophosphamide (2 $\mathrm{g} / \mathrm{m}^{2} \times 2$ days) and Granulocyte colony stimulating factor. Harvesting was done on day 11. The conditioning regimen used was Melphalan $\left(200 \mathrm{mg} / \mathrm{m}^{2}\right)$. During the conditioning, he developed neutropenia for which supportive measures were given.
Irradiated blood products were given for transfusions.

The patient engrafted successfully on day +14 . On day +16 post transplant he developed nausea, 6-7 episodes of vomiting and diarrhoea. The frequency of diarrhoea ranged from 14 to 21 times/ day. The stools were watery, non mucoid with no blood and with an average volume of $200 \mathrm{ml} / \mathrm{stool}$. The possibilities considered were infective diarrhoea, melphalan-induced diaarhoea or antibiotic associated colitis. There was no remarkable fever and no skin rash. Blood cultures were sterile. Repeated stool examinations showed no pus cells/RBCs, no ova/cyst, no opportunistic pathogens and negativity for giardia antigen. Repeatedly the bacterial and fungal cultures of the stool were negative for pathogenic organisms. The PCR for Cytomegalovirus was negative; as was the serology for Epstein Barr Virus and hepatitis A, E, B, C viruses and Clostridium difficile toxin assay. Liver function tests were normal. Despite administration of systemic antimicrobials, anti-motility drugs, anti-secretory drugs and probiotics, the diarrhoea was persistent. Hence a proctosigmoidoscopy was done on day +19 and a rectal biopsy was taken. The rectal biopsy showed moderate distortion of crypt architecture with crypt shortening, occasional fibro-muscular strands within the inter-crypt space and lamina propria showed minimal mononuclear cells (Figure 1). Staining for CMV, fungi and acid fast bacilli was negative. The patient was started on methylprednisolone @ $2 \mathrm{mg} /$ $\mathrm{kg} /$ day in two divided doses, following which there was a dramatic
Ann Hematol Oncol - Volume 4 Issue 4 - 2017 ISSN : 2375-7965 | www.austinpublishinggroup.com Nityanand et al. (c) All rights are reserved
Citation: Garg A, Yadav S and Nityanand S. Isolated Gastrointestinal Graft versus Host Disease in a Patient of Multiple Myeloma after Autologous Hematopoietic Stem Cell Transplantation. Ann Hematol Oncol. 2017; 4(4): 1146. 


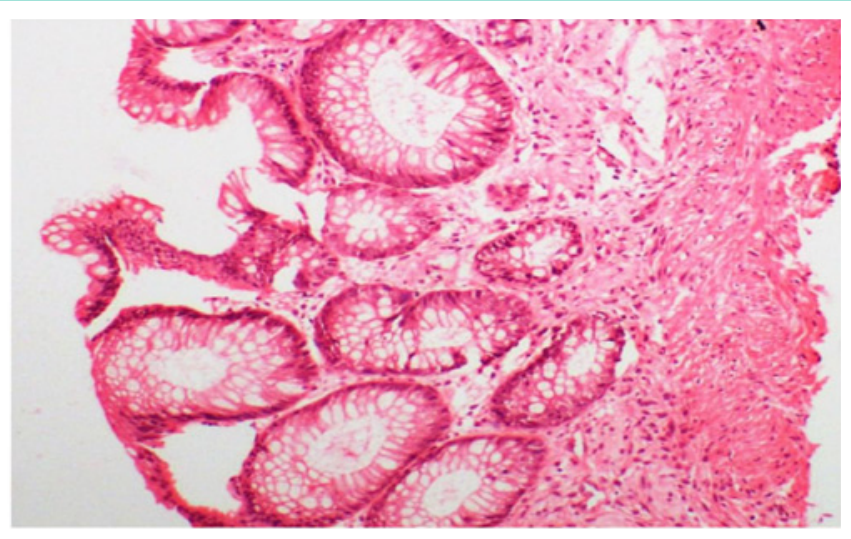

Figure 1: Rectal biopsy showing crypt distortion, with dilatation and increased fibrosis in the intercrypt space. The lamina propria showing moderate infiltration with mononuclear cells.

improvement in the nausea and diarrhoea and the anti-motility and anti-secretory agents could be stopped. The methylprednisolone was later changed to oral prednisolone and the patient was discharged on day +45 . At the time of discharge the stool frequency had decreased to three times/day. The bowel habits returned to normal in 2-3 weeks after discharge and prednisolone was gradually tapered and stopped over a period of 3 months. The patient has been in follow-up for past three years, with no recurrence of the GI symptoms and the disease continues to be in remission.

\section{Discussion}

GVHD following autologous HSCT is uncommon and its incidence has been reported to vary from $2-13 \%[3,4]$. It is seen more commonly in patients of multiple myeloma (MM) than in other haematological malignancies [3]. In particular, the risk for autologous GVHD is higher in patients undergoing tandem transplantation for $\mathrm{MM}(12 \%)$ than in those undergoing a single session of transplantation (0.9\%) [3]. In comparison to acute GVHD following allogeneic HSCT, acute GVHD following autologous HSCT tends to be milder. In most cases the involvement has been have been limited to the skin and gastrointestinal (GI) involvement is rare. In a case series reported by Holmberg, et al. 13\% (90/681) of patients developed GI GVHD after autologous HSCT. Only three of the 90 patients had diarrhoea and no patients had severe diarrhoea [4]. In another case series reported by Drobyski, et al. there was a $2 \%$ incidence of autologous GVHD in patients of multiple myeloma and among these patients, five developed a clinical syndrome consistent with GI GVHD. Four of these 5 patients ultimately expired due to complications attributed to steroid-refractory GI GVHD [3]. Amongst isolated case reports, Fidler, et al. described a case of autoGVHD with skin and gastrointestinal manifestations in a patient with MM, who ultimately deteriorated and expired despite steroid therapy [5]. Recently, Barbash, et al. described a case of spontaneous GI GVHD with predominant upper GI involvement in a patient of multiple myeloma who underwent autologous HSCT [6].

Isolated GI GVHD has been uncommonly reported perhaps because it is difficult to diagnose. Lazarus, et al. reported autologous GVHD in 9 patients of multiple myeloma and out of these 6 had isolated GI GVHD [7]. Cogbill, et al. demonstrated isolated GI
GVHD in 12 patients out which 6 cases expired [8]. The case series by Drobyski, et al. had 2 cases of isolated GI GVHD [3]. Krishna, et al. demonstrated spontaneous recurrent GI GVHD after a tandem autologous transplant for multiple myeloma with predominant lower GI symptoms and excellent response to enteric-coated budesonide therapy [9]. It is likely that isolated GI GVHD following autologous HSCT is unrecognized amongst other causes of diarrhoea like infection, drug toxicity and several patients may have subclinical disease. Persistent non-infective diarrhoea in MM patients following conditioning with Melphalan can be mistaken for melphalan-induced mucositis or antibiotic-associated colitis.

GI GVHD following autologous HSCT has been associated with a high mortality if not treated promptly. Case series reporting this entity have reported mortality as high as $50 \%$. In the case series by Drobyski, et al. out of the 2 cases with isolated GI GVHD, 1 died [3]. Six patients out of 12 with isolated GI GVHD, could not be salvaged in the study by Cogbill [8]. Therefore, patients who develop intractable diarrhoea after an autologous HSCT and a cause cannot be ascertained should undergo appropriate investigations including endoscopy and possibly mucosal biopsy for an early diagnosis of GI GVHD and in order to start steroid therapy promptly

In our patient, infective diarrhoea was almost ruled out since repeated stool cultures were sterile and other ancillary investigations were negative. Non-responsiveness to anti-motility and antisecretory agents suggested lesser possibility of antibiotic- associated and melphalan- associated diarrhoea. Another differential diagnosis could be an engraftment syndrome which also shows steroid responsiveness. However, it was an unlikely cause of such severe diarrhoea in our patient who did not have fever, rash or any evidence of vascular leak or multi-organ dysfunction.

Our case was unique and rare since we demonstrated isolated spontaneous GI GVHD following a single session of autologous HSCT and although the procto-sigmoidoscopy findings were normal, the rectal biopsy showed features consistent with GVHD. With prompt treatment with high dose steroids, our patient showed marked improvement in GI symptoms and good recovery.

\section{Conclusion}

GI GVHD should be considered in the differential diagnosis of severe unexplained diarrhoea following autologous HSCT in multiple myeloma when other causes have been ruled out. Appropriate investigations including endoscopy and biopsy are essential for a prompt diagnosis and initiation of early therapy with steroids to prevent mortality in this potentially treatable condition.

\section{References}

1. Jones RJ, Vogelsang GB, Hess AD, Farmer ER, Mann RB, Geller RB, et al. Induction of graft-versus-host disease after autologous bone marrow transplantation. Lancet. 1989; 1: 754-7.

2. Hood AF, Vogelsang GB, Black LP, Farmer ER, Santos GW. Acute graft-vshost disease. Development following autologous and syngeneic bone marrow transplantation. Arch Dermatol. 1987; 123: 745-750.

3. Drobyski WR, Hari P, Keever-Taylor C, Komorowski R, Grossman W. Severe autologous GVHD after hematopoietic progenitor cell transplantation for multiple myeloma. Bone Marrow Transplant. 2009; 43: 169-177.

4. Holmberg L, Kikuchi K, Gooley T, Adams KM, Schoch GH, Bensinger WI et al. Gastrointestinal graft-versus-host disease in recipients of autologous 
hematopoietic stem cells: Incidence, risk factors, and outcome. Biol Blood Marrow Transplant. 2006; 12: 226-234.

5. Fidler C, Klumpp T, Mangan K, Martin M, Sharma M, Emmons R, et al Spontaneous graft versus host disease occurring in a patient with multiple myeloma after autologous stem cell transplant. Am J Hematol. 2012; 87: 219 221.

6. Barbash B, Kramer S, Tzimas D, Saitta P. Graft-Versus-Host Disease of the Upper Gastrointestinal Tract After an Autologous Stem Cell Transplant. ACG Case Rep J. 2014; 2: 55-57.

7. Lazarus HM, Sommers SR, Arfons LM, Fu P, Ataergin SA, Kaye NM, et al. Spontaneous autologous graft-versus-host disease in plasma cell myeloma autograft recipients: flow cytometric analysis of hematopoietic progenitor cell grafts. Biol Blood Marrow Transplant. 2011; 17: 970-978.
8. Cogbill $\mathrm{CH}$, Drobyski WR, Komorowski RA. Gastrointestinal pathology of autologous graft-versus-host disease following hematopoietic stem cel transplantation: A clinicopathological study of 17 cases. Mod Pathol. 2010; 24: 117-125.

9. Krishna SG, Barlogie B, Lamps LW, Krishna K, Aduli F, Anaissie E. Recurrent Spontaneous Gastrointestinal Graft-Versus-Host Disease in Autologous Hematopoietic Stem Cell Transplantation. Clin Lymphoma Myeloma Leuk. 2010; 10: 17-21.
Ann Hematol Oncol - Volume 4 Issue 4 - 2017

ISSN : 2375-7965 | www.austinpublishinggroup.com

Nityanand et al. (C) All rights are reserved
Citation: Garg A, Yadav S and Nityanand S. Isolated Gastrointestinal Graft versus Host Disease in a Patient of Multiple Myeloma after Autologous Hematopoietic Stem Cell Transplantation. Ann Hematol Oncol. 2017; 4(4): 1146. 